\title{
Toxic Effects of Ochratoxin A on Calcium Metabolism during Chick Embryo Developmentand in Hatched Chicks
}

\section{-Author(s)}

\section{Elsayed MAE \\ Hatab $\mathrm{MH}^{\prime}$}

Elaroussi MA

Biological Applications Department, Nuclear Research Center, Atomic Energy Authority, Abou-Zaabal, P.O. 13759, Egypt.

\section{ABSTRACT}

The present study was carried out to study the effect of inovo ochratoxin A (OTA) injection in Highline layer eggs on calcium metabolism and blood biochemical parameters of embryos and after the hatch. At day 10 of embryonic development, one hundred and sixty-two fertile eggs were individually weighed and divided into two equal treatments. The first treatment (control) consisted of the individual injection of fertile eggs with $50 \mu \mathrm{L}$ sodium carbonate. In the second treatment (OTA), fertile eggs were individually injected with $12.5 \mathrm{ng}$ OTA dissolved in $50 \mu \mathrm{L}$ sodium carbonate. On days 12,14 , and 16 of incubation and at the hatch, serum calcium and inorganic phosphorus concentrations were lower $(p<0.05)$, while sodium, alkaline phosphatase and triiodothyronine concentrations were higher $(p<0.05)$ in the OTA-injected eggs compared with the controls. Serum potassium concentration was not affected $(p<0.05)$ by OTA treatment. Lower calcium and phosphorus levels were determined $(p<0.05)$ in the allantoic fluid of OTA-injected eggs compared with the controls. On days 12, 14, and 16 of incubation and at the hatch, lower whole body and yolk calcium and phosphorus, but not sodium levels, were measured $(p<0.05)$ in the OTA treatment compared with the controls. In conclusion, the injection of eggs with OTA reduced blood calcium and phosphorus levels, which were associated with reduced whole body and yolk content from these electrolytes. Therefore, ochratoxin A had a negative effect on calcium metabolism.

\section{INTRODUCTION}

Mycotoxins are secondary mold metabolites, and are ubiquitous contaminants of food and feed (O'Brien et al., 2001). In crop and animal production, the most important mycotoxins are the aflatoxins (AF) B1, $B 2, G 1, G 2$, ochratoxin $A(O T A)$, fumonisins (FB1, FB2), zearalenone (ZEA) and trichothecenes (O'Brien et al., 2001).

Ochratoxin A (OTA) is a mycotoxin produced by some toxigenic species of Aspergillus and Penicillium fungi, and it is an unavoidable contaminant of animal and human food sources (Mukhtar et al., 2010). Studies show that this mycotoxin can have nephrotoxic, hepatotoxic, neurotoxic, teratogenic and immunotoxic effects (El Khoury \& Atoui, 2010).

Ochratoxin A inhibits the accumulation of cartilage proteoglycans and general protein synthesis in a dose-related manner (Oliveira et al., 2002). Enhanced calcium uptake by the cells is frequently proposed as the cause of the disruption of cell morphological integrity by specific toxic chemicals. In an experimental study, administration of OTA to the female rabbits resulted in the skeletal defects in the developing embryos (Wangikar et al., 2004). 
The consumption of OTA-contaminated diets (2 $\mathrm{mg} / \mathrm{kg} \mathrm{PO}$ ) by three-week-old male broiler chickens for ten days reduced urinary fractional sodium content and potassium excretion (Glahn et al., 1991). On the other hand, Glahn et al. (1991) observed lower total plasma calcium levels and higher fractional calcium excretion in AF-fed broilers compared with the controls, and concluded the direct and indirect effects of AF on calcium and phosphorus metabolism may due a reduction in the endogenous synthesis of the parathyroid hormone (PTH) and of the renal sensitivity to PTH (Glahn et al., 1991). The supplementation of 2.5 ppm AF (Giroir et al., 1991) or 3.5 ppm AF (Smith et al., 1992) to broiler chicks for three weeks decreased serum calcium and phosphorus levels.

Therefore, the objective of the present experiment was to study the effects of injection of the mycotoxin ochratoxin $A$ in Highline layer eggs on the calcium metabolism and blood biochemistry of embryos and hatchlings.

\section{MATERIALS AND METHODS Location}

The present study was carried out at the Biological Applications Department, Nuclear Research Center, Atomic Energy Authority, Inshas City, Sharkia, Egypt.

\section{Eggs and birds}

One hundred and eighty Highline layer fertilized eggs (55-59 g) were used in this study. The eggs were generously donated by Miser Poultry Company (MIPCO). Eggs were individually weighed, and then incubated in a Victoria incubator (Guanzate Co, Italy) at $37.5^{\circ} \mathrm{C}$ and $60 \% \mathrm{RH}$, and turned every $2 \mathrm{~h}$ at a $45^{\circ}$ angle during the first 19 days of incubation.

\section{Experimental design}

On day 10 of embryonic development (di), eggs were examined by light candling to remove infertile eggs, and to determine the air cell border. Then,162 fertile eggs were individually weighed and divided into two equal groups with three replicates of 27 fertile eggs each. In the first group (control), each egg was injected in the air cell above the mark by $50 \mu \mathrm{L}$ sodium bicarbonate $(2 \%)$ using syringe $(21 \mathrm{G})$, while, each egg of the second group (OTA group) was injected in the air cell above the mark with 12.5 ng OTA dissolved in $50 \mu \mathrm{L}$ sodium bicarbonate (2\%).

\section{Blood samples}

Blood samples were collected from the vitelline vein of nine embryos per group (three embryos per replicate) on 12, 14 and 16di. At hatch, blood samples were collected from the jugular vein of nine chicks per group (three hatchlings per replicate). Blood samples were stored at room temperature for 30 min to allow blood clotting. The blood was then centrifuged to separate the serum, which was frozen and stored at $-20^{\circ} \mathrm{C}$ until biochemical and hormonal analyses.

\section{Biochemical analysis}

Calcium (Ca), inorganic phosphorus (Pi), and alkaline phosphatase (ALP) serum levels were colorimetrically determined using commercial kits (Stanbio Company, USA) and measured on computerized spectrophotometer (model Spectronic 1201, Milton Roy, USA). Sodium ( $\mathrm{Na}$ ) and potassium ( $\mathrm{K}$ ) serum levels were determined using a flamephotometer (model PFP7/C, Cole-Parmer, UK). Finally, triiodothyronine $\left(T_{3}\right)$ concentration was determined using commercial radioimmunoassay (RIA) kit (IZOTOP Co., INSTITUTE OF ISOTOPES Ltd., http://www.izotop.hu) and samples were counted on a Packard Gamma Counter (model 540501 RIA SAR, USA). Chorioallantoic fluid was collected to determine calcium and phosphorus concentrations.

On the same days (12, 14 and $16 \mathrm{di})$, nine embryos per group (three embryos per replicate) without the embryonic yolk sac were individually weighed $(\mathrm{g})$ then burnt to ash at $550^{\circ} \mathrm{C}$ and $0.2 \mathrm{~g}$ of ash were solubilized in sulfuric acid to determine calcium, phosphorus, sodium, and potassium concentrations.

Nine hatchlings per group (three per replicate) were frozen and burnt to ash as previously described to determine whole body and residual yolk concentrations of calcium, phosphorus, sodium and potassium.

\section{Statistical analysis}

Data were statistically analyzed by one-way analysis of variance using the General Liner Model Procedure of the SAS software (SAS Institute, 2002). Mean values were compared using Duncan's Multiple Range Test (Duncan, 1955) at $p<0.05$. The model applied was:

$Y_{i}=\mu+T_{i}+E_{j}$

Where:

$Y_{i}=$ any value from the overall population.

$\mu=$ overall mean.

$T_{i}=$ the effect of the $i^{\text {th }}$ treatment $(i=1$, control; 2 , OTA).

$E_{j}=$ the random error associated with the $j^{\text {th }}$ individual. 


\section{RESULTS}

Table 1 presents the effect of OTA injection infertile eggs on blood biochemical parameters and hormone concentrations. On days 12, 14 and 16 of incubation and at the hatch, the OTA treatment resulted in lower $(p<0.05)$ serum calcium and inorganic phosphorus concentrations compared with the control. In addition, higher serum ALP, sodium, and $T_{3}$ levels were observed $(p<0.05)$ in embryos and hatchlings of the OTA group compared with the controls. Serum potassium levels were not affected $(p<0.05)$ by OTA treatment in any of the evaluated embryos or hatchlings.

Table 1 - Effect of OTA injection on selected serum biochemical parameters and hormonal concentrations of embryos and hatchlings.

\begin{tabular}{|c|c|c|c|c|c|}
\hline \multirow{2}{*}{ Parameters } & \multirow{2}{*}{ Treat. } & \multicolumn{3}{|c|}{ Embryonic age (day) } & \multirow{2}{*}{ At hatch } \\
\hline & & 12 & 14 & 16 & \\
\hline \multirow{2}{*}{ Calcium (mg/dL) } & Cont. & $6.33 \pm 0.02^{a *}$ & $7.44 \pm 0.1^{\mathrm{a}}$ & $9.04 \pm 0.09^{a}$ & $10.84 \pm 0.1^{\mathrm{a}}$ \\
\hline & OTA & $4.48 \pm 0.02^{b}$ & $5.97 \pm 0.1^{b}$ & $7.30 \pm 0.09^{b}$ & $8.12 \pm 0.1^{b}$ \\
\hline \multirow{2}{*}{ Phosphorus (mg/dL) } & Cont. & $3.77 \pm 0.06^{a}$ & $4.24 \pm 0.08^{a}$ & $4.98 \pm 0.04^{a}$ & $5.69 \pm 0.1^{a}$ \\
\hline & OTA & $3.10 \pm 0.06^{b}$ & $3.50 \pm 0.08^{b}$ & $3.40 \pm 0.04^{b}$ & $4.21 \pm 0.1^{b}$ \\
\hline \multirow{2}{*}{ Alkaline phosphatase (IU/L) } & Cont. & $43.72 \pm 0.3^{b}$ & $37.58 \pm 0.2^{b}$ & $28.76 \pm 0.2^{b}$ & $25.24 \pm 0.2^{b}$ \\
\hline & OTA & $48.58 \pm 0.3^{a}$ & $41.54 \pm 0.2^{\mathrm{a}}$ & $33.70 \pm 0.2^{\mathrm{a}}$ & $28.58 \pm 0.2^{\mathrm{a}}$ \\
\hline \multirow{2}{*}{ Sodium (MEq/L) } & Cont. & $101.82 \pm 0.6^{b}$ & $123.21 \pm 0.7^{b}$ & $136.19 \pm 0.7^{b}$ & $142.87 \pm 0.8^{b}$ \\
\hline & OTA & $123.91 \pm 0.6^{a}$ & $139.62 \pm 0.7^{a}$ & $149.31 \pm 0.7^{\mathrm{a}}$ & $153.68 \pm 0.8^{a}$ \\
\hline \multirow{2}{*}{ Potassium MEq/L) } & Cont. & $5.28 \pm 0.02$ & $6.55 \pm 0.02$ & $7.61 \pm 0.04$ & $8.31 \pm 0.03$ \\
\hline & OTA & $5.19 \pm 0.02$ & $6.21 \pm 0.02$ & $6.96 \pm 0.04$ & $7.68 \pm 0.03$ \\
\hline \multirow{2}{*}{ Triiodothy. (ng/mL) } & Cont. & $1.35 \pm 0.04^{b}$ & $1.74 \pm 0.04^{b}$ & $2.07 \pm 0.06^{b}$ & $2.22 \pm 0.03^{b}$ \\
\hline & OTA & $1.77 \pm 0.04^{\mathrm{a}}$ & $2.34 \pm 0.04^{\mathrm{a}}$ & $2.53 \pm 0.06^{a}$ & $2.88 \pm 0.03^{a}$ \\
\hline
\end{tabular}

*Values are expressed means \pm standard error of the mean.

$a, b$, Means with different superscripts within the same age indicate significant differences between treatments by Duncan's Multiple Range Test ( $p<0.05)$.

$\mathrm{N}=9$ per treatment.

Table 2 presents the effect of OTA injection infertile eggs on calcium and phosphorus concentrations in the allantoic fluid. On days 12, 14 and 16 of embryonic development, lower calcium and phosphorus concentrations $(p<0.05)$ were determined in OTA group compared with the control group.

Table 2 - Effect of OTA injection on the calcium and phosphorus concentrations the allantoic fluid of chicken embryos.

\begin{tabular}{lcccc}
\hline \multirow{2}{*}{ Parameters } & \multirow{2}{*}{ Treat. } & \multicolumn{3}{c}{ Embryonic age (day) } \\
\cline { 3 - 5 } & & 12 & 14 & 16 \\
\hline Calcium & Cont. & $1.79 \pm 0.06^{\mathrm{a}}$ & $2.27 \pm 0.04^{\mathrm{a}}$ & $2.78 \pm 0.02^{\mathrm{a}}$ \\
(mg/dL) & OTA & $1.25 \pm 0.06^{\mathrm{b}}$ & $1.79 \pm 0.04^{\mathrm{b}}$ & $2.15 \pm 0.02^{\mathrm{b}}$ \\
Phosphorus & Cont. & $1.03 \pm 0.02^{\mathrm{a}}$ & $1.20 \pm 0.01^{\mathrm{a}}$ & $1.43 \pm 0.02^{\mathrm{a}}$ \\
(mg/dL) & OTA & $0.70 \pm 0.02^{\mathrm{b}}$ & $0.94 \pm 0.01^{\mathrm{b}}$ & $1.15 \pm 0.02^{\mathrm{b}}$ \\
\hline
\end{tabular}

*Values are expressed as means \pm standard error of the mean.

$a, b$, Means with different superscripts within the same age indicate significant differences between treatments by Duncan's Multiple Range Test $(p<0.05)$.

$\mathrm{N}=9$ per treatment.
Table 3 shows the effects of OTA injection infertile eggs on yolk calcium, phosphorus, sodium and potassium concentrations. On days 12, 14, and 16 of incubation and at the hatch, OTA injection resulted lower yolk calcium and phosphorus levels $(p<0.05)$ and higher sodium levels $(p<0.05)$ compared with the control treatment, while, yolk potassium concentration was not affected $(p>0.05)$ by the OTA treatment.

The effects of OTA injection infertile eggs on whole body calcium, phosphorus, sodium, and potassium concentrations are shown in Table 4 . On days 12, 14, and 16 of incubation and at the hatch, whole body calcium and phosphorus levels were significantly lower $(p<0.05)$ and sodium levels were significantly higher $(p<0.05)$ in the OTA group than in the control group. Potassium levels were not significantly affected by OTA treatment ( $p>0.05$ ). 
Table 3 - Effect of OTA injection on calcium, phosphorus, sodium and potassium concentrations in the yolk of embryos and hatchlings.

\begin{tabular}{|c|c|c|c|c|c|}
\hline \multirow{2}{*}{ Parameters } & \multirow{2}{*}{ Treat. } & \multicolumn{3}{|c|}{ Embryonic age (day) } & \multirow{2}{*}{ At hatch } \\
\hline & & 12 & 14 & 16 & \\
\hline \multirow{2}{*}{ Calcium (ppm) } & Cont. & $180.82 \pm 0.2^{a}$ & $200.57 \pm 0.7^{a}$ & $230.40 \pm 0.7^{a}$ & $250.92 \pm 0.15^{a}$ \\
\hline & OTA & $160.98 \pm 0.2^{b}$ & $170.44 \pm 0.7^{b}$ & $200.81 \pm 0.7^{b}$ & $220.12 \pm 0.15^{b}$ \\
\hline \multirow{2}{*}{ Phosphorus (ppm) } & Cont. & $550.12 \pm 0.3^{a}$ & $600.34 \pm 0.3^{a}$ & $630.24 \pm 0.3^{a}$ & $660.99 \pm 0.4^{a}$ \\
\hline & OTA & $490.21 \pm 0.3^{b}$ & $540.54 \pm 0.3^{b}$ & $580.66 \pm 0.3^{b}$ & $590.47 \pm 0.4^{b}$ \\
\hline \multirow{2}{*}{ Sodium (ppm) } & Cont. & $60.12 \pm 0.8^{b}$ & $60.58 \pm 0.9^{b}$ & $70.29 \pm 0.9^{b}$ & $70.95 \pm 0.5^{b}$ \\
\hline & OTA & $70.25 \pm 0.8^{a}$ & $70.84 \pm 0.9^{a}$ & $80.18 \pm 0.9^{a}$ & $80.76 \pm 0.5^{a}$ \\
\hline \multirow{2}{*}{ Potassium (ppm) } & Cont. & $170.66 \pm 0.7$ & $190.92 \pm 0.8$ & $190.85 \pm 0.8$ & $210.65 \pm 0.5$ \\
\hline & $\mathrm{OA}$ & $160.99 \pm 0.7$ & $190.67 \pm 0.8$ & $190.91 \pm 0.8$ & $210.12 \pm 0.5$ \\
\hline
\end{tabular}

*Values are expressed as means \pm standard error of the mean.

$a, b$, Means with different superscripts within the same age indicate significant differences between treatments by Duncan's Multiple Range Test ( $p<0.05)$.

$\mathrm{N}=9$ per treatment. $\mathrm{ppm}=\mathrm{mg} / \mathrm{kg}$ dry weight.

Table 4 - Effect of OTA embryo injection on whole body calcium, phosphorus, sodium and potassium concentrations of embryos and hatchlings.

\begin{tabular}{lccccc}
\hline \multirow{2}{*}{ Parameters } & Treat. & \multicolumn{4}{c}{ Embryonic age (day) } \\
\cline { 3 - 5 } & & 12 & 14 & 16 & \multirow{2}{*}{ At hatch } \\
\hline Calcium & Cont. & $170.45 \pm 0.6^{\mathrm{a}}$ & $340.21 \pm 0.3^{\mathrm{a}}$ & $770.66 \pm 0.9^{\mathrm{a}}$ & $1390.1 \pm 0.11^{\mathrm{a}}$ \\
(ppm) & OTA & $130.52 \pm 0.6^{\mathrm{b}}$ & $290.12 \pm 0.3^{\mathrm{b}}$ & $520.09 \pm 0.9^{\mathrm{b}}$ & $910.54 \pm 0.11^{\mathrm{b}}$ \\
Phosphorus & Cont. & $80.31 \pm 0.3^{\mathrm{a}}$ & $120.62 \pm 0.3^{\mathrm{a}}$ & $220.09 \pm 0.7^{\mathrm{a}}$ & $310.77 \pm 0.7^{\mathrm{a}}$ \\
(ppm) & OTA & $60.92 \pm 0.3^{\mathrm{b}}$ & $90.23 \pm 0.3^{\mathrm{b}}$ & $180.35 \pm 0.7^{\mathrm{b}}$ & $240.82 \pm 0.7^{\mathrm{b}}$ \\
Sodium & Cont. & $740.05 \pm 0.6^{\mathrm{b}}$ & $740.04 \pm 0.9^{\mathrm{b}}$ & $880.99 \pm 0.4^{\mathrm{b}}$ & $960.22 \pm 0.5^{\mathrm{b}}$ \\
(ppm) & OTA & $860.09 \pm 0.6^{\mathrm{a}}$ & $890.99 \pm 0.9^{\mathrm{a}}$ & $970.19 \pm 0.4^{\mathrm{a}}$ & $1130.77 \pm 0.5^{\mathrm{a}}$ \\
Potassium & Cont. & $690.44 \pm 0.2$ & $720.88 \pm 0.2$ & $840.84 \pm 0.1$ & $910.67 \pm 0.8$ \\
(ppm) & OTA & $680.85 \pm 0.2$ & $730.93 \pm 0.2$ & $850.21 \pm 0.1$ & $890.72 \pm 0.8$ \\
\hline
\end{tabular}

*Values are expressed as means \pm standard error of the mean.

$a, b$, Means with different superscripts within the same age indicate significant differences between treatments by Duncan's Multiple Range Test ( $p<0.05$ ).

$\mathrm{N}=9$ per treatment. $\mathrm{ppm}=\mathrm{mg} / \mathrm{kg}$ dry weight.

\section{DISCUSSION}

The injection of chicken embryos with OTA reduced serum calcium and phosphorus levels compared with the control treatment, but did not influence serum potassium levels. These results are in agreement with the results of Kececi et al. (1998), Gokhan et al. (2005) in broilers and Qubih (2012) in layers, who found that mycotoxicosis (aflatoxicosis and ochratoxicosis) lowered serum calcium and phosphorus levels. Gokhan et al. (2005) did not observe any significant changes in the blood potassium level of broilers fed aflatoxin either.

Serum sodium levels significantly increased with OTA injection compared with the saline solution, in agreement with Glahn et al. (1991), who found that after $10 \mathrm{~d}$ of aflatoxin treatment (AF; $2 \mathrm{mg} / \mathrm{kg}$ per os), serum sodium levels increased, but no statistically significant changes in serum potassium levels between AF-treated and control birds.

Although the role of alkaline phosphatases (ALP) in bone formation has not been fully elucidated yet, the activity of ALP is used an indicator of the "normality" of bone development (Mcwhinne \& Robert, 1973). Firschein \& Urist (1971) indicated that the presence or absence of the pituitary gland influences the growth of long bones, total bone alkaline phosphatase content, and the specific activity of this enzyme in the bone. In normal chicken embryos, femur growth is roughly linear in the latter half of incubation (on days 13-15). Together with the increase in bone mass, total alkaline phosphatase activity increases. Our results were agreement with Denli et al. (2008) who found that a diet contaminated with OTA significantly $(p<0.05)$ increased serum ALP activity in layers compared with a non-contaminated diet.

OTA treatment increased serum triiodothyronine levels. Our data are in agreement with Hatab (2003) and Elaroussi et al. (2006), who reported that the presence of OTA in broiler diets caused a significant increase in serum triiodothyronine concentration when compared with the control birds. Those authors concluded that the effects of OTA on thyroid hormones were dose - and time - dependent. El-Barkouky \& Abu-Taleb 
(2008) also observed that broiler chicks subjected to dietary intoxication with OTA at 50 and 100 ppb from one day to five weeks of age developed a significant increase in serum $T_{3}$ concentration at both examined OTA levels compared with the control chicks.

Yolks contain more than $90 \%$ of the calcium, iron, phosphorus, zinc, thiamine, B6, folate, and B12, and pantothenic acid present in the chicken egg. In addition, the yolk includes all of the fat-soluble vitamins A, D, E, and $K$ of the egg, as well as all of essential fatty acids (EFAs), as determined in the chart of nutrient amounts per $100 \mathrm{~g}$ of egg yolk (Kruszelnicki, 2007). Ochratoxin A causes poor shell strength (Hermann, 2002), as previously demonstrated by the rubbery eggshells, which break more readily than normal field, observed during field outbreaks of ochratoxicosis (Jewers, 1990).

Dietary ochratoxin, but not aflatoxin, increased the bone elasticity of young chickens (William et al., 1980), who reported that bone material properties can be altered during mycotoxicoses. Therefore, the bones of young chickens suffering ochratoxicosis may be more brittle than normal bones (William et al., 1980). In the present study, the injection of embryos with OTA resulted in significantly lower calcium and phosphorus concentrations in yolk and in the whole body of embryos and hatchlings.

\section{CONCLUSION}

In conclusion, the injection of OTA chicken eggs with reduced yolk calcium and phosphorus levels, resulting in a reduction of the concentrations of these electrolytes in the serum and whole body of embryos and hatchlings. Therefore, ochratoxin A had a negative effect on calcium metabolism.

\section{REFERENCES}

Denli M, Blandon JC, Guynot ME, Salado S, Perez JF. Efficacy of a new ochratoxin-binding agent (OcraTox) to counteract the deleterious effects of ochratoxin A in laying hens. Poultry Science 2008;87:22662272

Duncan DB. Multiple range and multiple F test. Biometrics 1955;11:1.

El Khoury A, Atoui A. Ochratoxin A: general overview and actual molecular status. Toxins 2010;2(4):461-493.

Elaroussi MA, Mohamed FR, El Barkouky EM, Atta AM, Abdou AM, Hatab $\mathrm{MH}$. Experimental ochratoxicosis in broiler chickens. Avian Pathology 2006;35(4):263-269.

El-Barkouky EM, Abu-Taleb AM. The role of vitamin C in improving the performance of male broiler chickens feed ration contaminated with ochratoxin. Egyptian Journal of Applied Sciences 2008;23(2A):1-12

Firschein HE, Urist MR. The induction of alkaline phosphatase by extraskeletal implants of bone matrix. Calcified Tissue Research 1971;(7):108-113.
Giroir LE, Huff WE, Kubena LF, Harvey RB, Elissalde MH, Witsel DA, et al. The individual and combined toxicity of kojic acid and aflatoxin in broiler chickens. Poultry Science 1991;70:1351-1356.

Glahn RP, Beers KW, Bottje WG, Wideman RF, Huff WE, Thomas W. Aflatoxicosis alters avian renal function, calcium, and vitamin $D$ metabolism. Journal of Toxicology Environmental Health 1991;34:309321.

Gokhan E, Dinc E, Mehmet A, Fatma A, Levent A. The effects of aflatoxin and sodium bentonite combined and alone on some blood electrolyte levels in broiler chickens. Turkish Journal of Veterinary Animal Science 2005;29:601-605

Hatab MH. Determination of the toxic effects of ochratoxin a on broiler performance and immune system response by the use of nuclear techniques [thesis]. Cairo: Faculty of Agriculture Cairo University; 2003.

Hermann T. Mycotoxins in feed grains and ingredients on feed manufacturing [technical bulletin, MF-206]. Manhattan (KS): Agricultural Experiment Station and Extension; 2002.

Jewers K. Mycotoxins and their effect on poultry production. Options Méditerranéennes: Serie A, 1990;7:195-202.

Kececi T, OUuz H, KurtoUlu V. Effects of polyvinylpolypyrrolidone, synthetic zeolite and bentonite on serum biochemical and hematological characters of broiler chickens during aflatoxicosis. BritishPoultry Science 1998;39:452-458

Kruszelnicki KS. Double-yolked eggs and chicken development. Sidney: Australian Broadcasting Corporation; 2007. p.12-09.

Mcwhinnie DJ, Robert CT.The influence of hypophysectomy on bone growth and alkaline phosphatase activity in the chick embryo. Journal of Embryology and Experimental Morphology 1973;29:515-527.

Mukhtar A, Gilani AH, Bhatty N. Some nutritional and microbiological aspects of apples of common varieties available for household consumption. Journal of Animal and Plant Sciences 2010;20:253-257.

O'Brien E, Heussner AH, Dietrich DR. Species-, sex-, and cell type-specific effects of ochratoxin A and B. Toxicological Sciences 2001;63:256-264.

Oliveira CAF, Rosmaninho JF, Butkeraitis P, Corre B, Reis TA, Guerra JL, et al. Effect of low levels of dietary aflatoxin B1 on laying Japanese quail. Poultry Science 2002;81:976-980.

Qubih TS. Relationship between mycotoxicosis and calcium during preproduction period in layers. Iraqi Journal of Veterinary Sciences 2012;(26):11-14.

SAS Institute. SAS/STAT user's guide: version 8.2. Cary; 2002

Senyuva HZ, Gilbert J, Ozcan S, Ulken U. Survey of ochratoxin A and afaltoxin B1 in dried figs in Turkey using a single laboratory validated alkaline extraction method for ochratoxin A. Journal of Food Protection 2005;68:1512-1515

Smith EE, Kubena LF, Braithwaite CE, Harvey RB, Phillips TD, Reine AH. Toxicological evaluation of aflatoxin and cyclopiazonic acid in broiler chickens. Poultry Science 1992;71:1136-1144.

Wangikar PB, Dwivedi P, Sinha N. Effects in rats of simultaneous prenatal exposure to ochratoxin A and aflatoxin B1. I. Maternal toxicity and fetal malformations. Birth Defects Research: Part B 2004;71:343-351.

William EH, John AD, Pat BH, Donald DH, Robert EP, Alex C. Evaluation of bone strength during Aflatoxicosis and Ochratoxicosist. Applied and Environmental Microbiology 1980;102-107. 
